\title{
O Sutiã e Seus Precursores: uma análise estrutural e diacrônica
}

- Rosiane Pereira Alves'

- Laura Bezerra Martins²

\section{P.459-482}




\title{
O Sutiã e Seus Precursores: uma análise estrutural e diacrônica
}

\section{RESUMO}

Este artigo apresenta uma análise estrutural e diacrônica das roupas íntimas usadas para vestir as mamas femininas. Privilegiou a revisão de literatura enquanto fonte de dados. Estes revelaram que as estruturas configurativas dos precursores - protossutiãs e espartilhos - foram parcialmente transferidas para o sutiã. Porém, enquanto os protossutiãs e os espartilhos atuaram como mantenedores de um modelo de status quo de mulheres que não precisavam trabalhar, o sutiã contribuiu para a mudança desse paradigma. Sua criação, adoção e popularização ocorreram no início do século $X X$, sob influência das demandas sociais do mundo do trabalho e do desenvolvimento do prêt-à-porter.

Palavras-chave: protossutiã, espartilho, sutiã.

\section{The Bra and Its Precursors: a structural and diachronic analysis}

\begin{abstract}
This paper presents a structural and diachronic analysis of the clothes worn to dress the female breasts. It privileged the literature review as a data source. These revealed that the configurational structures of the precursors - protossutians and corsets - were partially transferred to the bra. However, while the protossutians and corsets acted as maintainers of a status quo model of women who were not need worked, the bra contributed to a change in that paradigm. Its creation, adoption and popularization occurred in the early twentieth century, influenced by the demands of the world of work and the development of ready-to-wear.
\end{abstract}

Keywords: protossutian, corset, bra 


\section{INTRODUÇÃO}

Apesar da roupa ter surgido na pré-história, as vestes íntimas foram mais fortemente adotadas durante a idade média. Todavia, sua popularização é um fenômeno do século $X X$.

Desde então, tem sido largamente usada, segundo Salen (2011) com o objetivo de: 1) manter a roupa externa limpa; 2) tornar o uso da roupa externa mais confortável e flexível, pela diminuição do número de forros; 3) atuar como base, alterando a forma do corpo conforme o desejo individual ou os ditames da moda.

Entretanto, o que classifica uma peça de roupa como íntima, segundo Rosseti (1995), é o contato direto com a pele. Para Steele (1997), este tipo de roupa ocupa uma posição intermediária, dado que uma pessoa em vestes íntimas pode ser considerada, simultaneamente, vestida ou despida.

Inclusive, é esse caráter intermediário que pôs as vestes íntimas, ao longo do tempo, no limite entre a sensualidade e a necessidade de uso no contexto social. Além disso, as roupas íntimas usadas para vestir as mamas, em termos históricos e progressivos, podem ser classificadas em três principais categorias: protossutiãs, espartilhos e sutiãs.

Nesta perspectiva, buscou-se saber quais as características estruturais dessas três categorias e as possíveis implicações do uso, no papel social assumido pelas mulheres ao longo do tempo.

Portanto, o objetivo desse estudo foi analisar estruturalmente e diacronicamente as três categorias de roupas íntimas usadas para vestir as mamas femininas. 
Os dados foram levantados por meio da revisão literária. No primeiro momento, as informações obtidas foram analisadas e, descrita a estrutura configurativa de cada uma das categorias, associando forma e função. Posteriormente, a configuração das vestes foi relacionada ao papel social exercido pelas mulheres.

Segundo Bonsiepe (1984), a análise diacrônica do desenvolvimento histórico é útil para demonstrar as mudanças do produto ao longo do tempo.

Enquanto que, os elementos configurativos determinam as características do produto e podem ser classificados em macroelementos e microelementos. Os macroelementos são aqueles percebidos mais facilmente, como forma, material, superfície. Enquanto os microelementos participam da impressão geral da configuração, mas não são percebidos de imediato. (LÖBACH, 2001).

Ainda segundo Löbach (2001), o elemento mais importante da figura é a forma. A forma havia sido definida por Wong (1998) como a aparência visual total de um desenho, composta de unidades de forma ou módulos, que podem ser constituídas por elementos menores, denominados de subunidades.

Neste artigo, foi adotado o termo elemento configurativo de Löbach (2001) para referenciar as diferentes partes das vestes íntimas. $\mathrm{E}$ os termos forma, unidade da forma e subunidade da forma de Wong (1998) para tratar dos vários subsistemas que compõem os espartilhos e os sutiãs. Por exemplo, a unidade da forma alça pode ser formada pelas subunidades elástico e reguladores. A unidade da forma taça pode ser constituída das subunidades tecido externo, enchimento espumado, forro e aro.

\section{PROTOSSUTIÃS}

As primeiras vestes usadas para cobrir as mamas foram os protossutiãs. Estes surgiram na civilização grega helenísticas, no início do Primeiro Milênio. Recebeu diferentes nomenclaturas tais como: Apodesme, Mastodeton, Fascia, Mamilare, Strophium. 


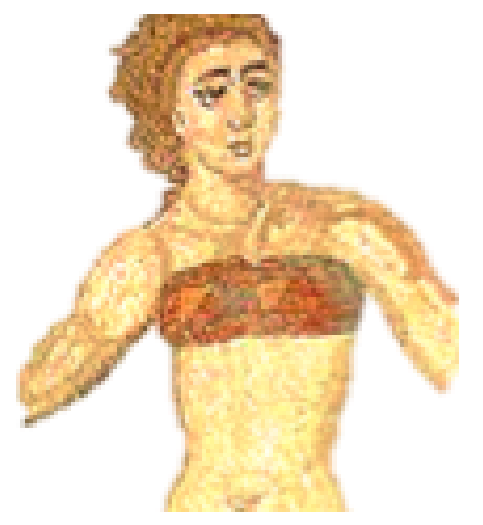

Figura 1: Faixa usada em Roma. Fonte: Boucher (2010).

\subsection{Forma e função dos protossutiãs}

Os protossutiãs eram configurados na forma de uma tira de pano, com variações na cor, no material e no uso, associadas as funções que exerciam. Por exemplo, o Apodesme era enrolada sob os seios. Enquanto o Mastodeton, faixa na cor vermelha, era usada pelas mulheres jovens em volta do busto (FONTANEL, 1998).

A Fascia, era usado pelas romanas, no início do Império (27 a.C.), para diminuir o tamanho dos seios (Figura1). E, se as mamas crescessem demasiadamente, era usado o Mamilare - de couro macio, que comprimia o busto (BOUCHER, 2010).

As mulheres bárbaras usavam o Strophium, uma espécie de echarpe que envolvia os seios, sustentando-os sem comprimir (FONTANEL, 1998).

Todavia, de acordo com Fontanel (1998), com a queda do Império Romano (476 d.C.) e as grandes invasões dos celtas e dos germânicos, a preocupação em sustentar e comprimir os seios perdeu sua importância. E as mulheres cristãs da Idade Média (séculos $\mathrm{V}-\mathrm{XV}$ ), deixaram seus bustos livres sob as túnicas, durante vários séculos. Os seios apenas voltaram a ser cobertos na época gótica, para adequar o corpo feminino às novas vestes externas ajustadas ao corpo (XII-XVI).

Para manter o corpo à imagem das colunas góticas, surgiu o que alguns historiadores chamaram de antecessor do espartilho - o Bliaud, um tipo de corpete amarrado por trás ou pelo lado que apertava o busto e era costurado a uma saia plissada (BOUCHER, 2010).

Alguns desses coletes e corpetes eram costurados no corpo pela manhã e descosturados à noite. Muitas tentativas empíricas foram feitas para encontrar novos sistemas de fechamento e de ajuste ao corpo. Pode-se, inclusive sugerir que se tratavam de iniciativas ergonômicas, a fim de adaptar o modo de vestir dos coletes e corpetes às necessidades de suas usuárias.

Posteriormente, as faixas para sustentar os seios, usadas por cima das túnicas, reapareceram por 
um período em decorrência do "puritanismo cristão da Idade Média", que, ao substituir a virtude romana, cuidava para que as novas liberdades indumentárias não cometessem excessos (FONTANEL, 1998, p.18).

Depois do século $X V$, as roupas íntimas se tornaram mais pesadas e rígidas. Foi criado, então, o Vasquim - corpete sem manga, muito justo, com forro de tecido pespontado e reforçado por fios de latão -, que era usado por cima da camisa e amarrado nas costas.

Em síntese, os protossutiãs exerceram funções como cobrir, achatar, comprimir, diminuir e sustentar as mamas, por vezes modificando a forma original do corpo (Quadro 1).

\begin{tabular}{|c|c|c|c|}
\hline Período & Região & Modelo e Forma & Função \\
\hline \multirow{6}{*}{$\begin{array}{l}\text { Antiguidade } \\
3500 \text { a.C. - } \\
476 \text { d.C. }\end{array}$} & Grécia: & Tiras drapeadas. & Cobrir, achatar. Silhueta androgênica. \\
\hline & \multirow{2}{*}{$\begin{array}{l}\text { Grécia } \\
\text { Helenística: }\end{array}$} & $\begin{array}{l}\text { Apodesme - Tiras ou } \\
\text { faixas. }\end{array}$ & Apoiar e controlar as mamas. \\
\hline & & $\begin{array}{c}\text { Mastodeton - faixa } \\
\text { estreita. }\end{array}$ & Envolver as mamas das jovens. \\
\hline & \multirow{3}{*}{ Roma: } & Fascia & Diminuir as mamas. \\
\hline & & $\begin{array}{l}\text { Mamilare - couro } \\
\text { macio. }\end{array}$ & Comprimir mamas grandes. \\
\hline & & Strophium & $\begin{array}{c}\text { Sustentar, sem pressionar. Usado por } \\
\text { mulheres bárbaras. }\end{array}$ \\
\hline $\begin{array}{l}\text { Idade Média } \\
\quad(\mathrm{V}-\mathrm{XV})\end{array}$ & $\begin{array}{l}\text { Europa } \\
\text { XII-XIII }\end{array}$ & $\begin{array}{l}\text { Bliaud - corpete } \\
\text { amarrado por trás }\end{array}$ & $\begin{array}{c}\text { Apertar o busto. Era costurado numa saia } \\
\text { plissada. }\end{array}$ \\
\hline
\end{tabular}

Quadro 1: Forma e Função dos Protossutiãs.

Fonte: Compilação da autora com base em

Boucher (2010) e Fontanel (1998).

\subsection{A influência dos protossutiãs no papel social das mulheres}

$\mathrm{Na}$ maioria dos casos, os protossutiãs compuseram as vestes das mulheres que não precisavam trabalhar. As escravas permaneceram com as mamas expostas. 


\section{ESPARTILHOS E CORSET}

O termo espartilho nomeia as peças íntimas fechadas nas costas por cordões (Figura 2). São denominadas, também, de corpetes, cintas, bustiês e similares. Sua rigidez, resultante da modelagem estruturada por barbatanas, tinha a função de controlar o corpo, modelando-o e impondo-lhe uma silhueta considerada elegante - postura reta pela sustentação da coluna (BARBIER e BOUCHER, 2010; BERG, 2015).

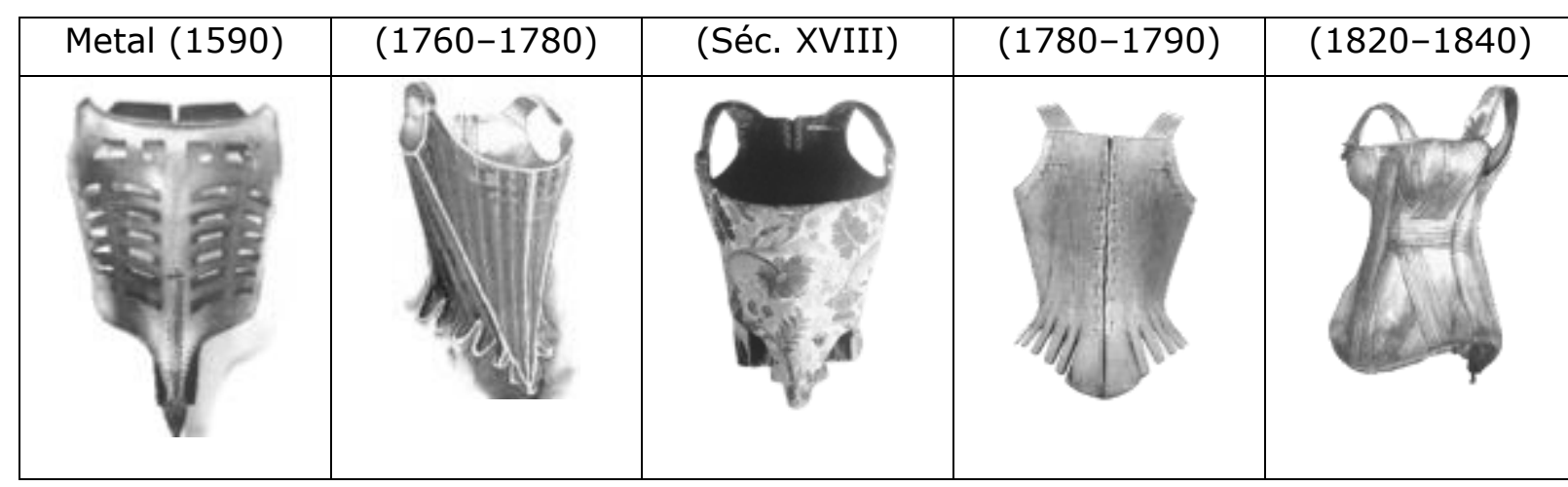

Figura 2: Espartilhos compilados pela autora.
Fonte:
Fonte:
Fonte: Barbier e Berg (2015).
Boucher (2010).
Fonte:
Folli (2010).
Fonte:
Berg (2015).

Enquanto que, o termo corset, formado pelas palavras corps (corpo) e serrer (fortemente apertado), segundo Berg (2015), foi adotado para nomear as peças que apresentavam frente e costas abertas. A abertura da frente era montada com uma haste de metal com fechos, denominado busk, inventada em 1830. As amarrações nas costas serviam para controlar o ajuste (Figura 3).

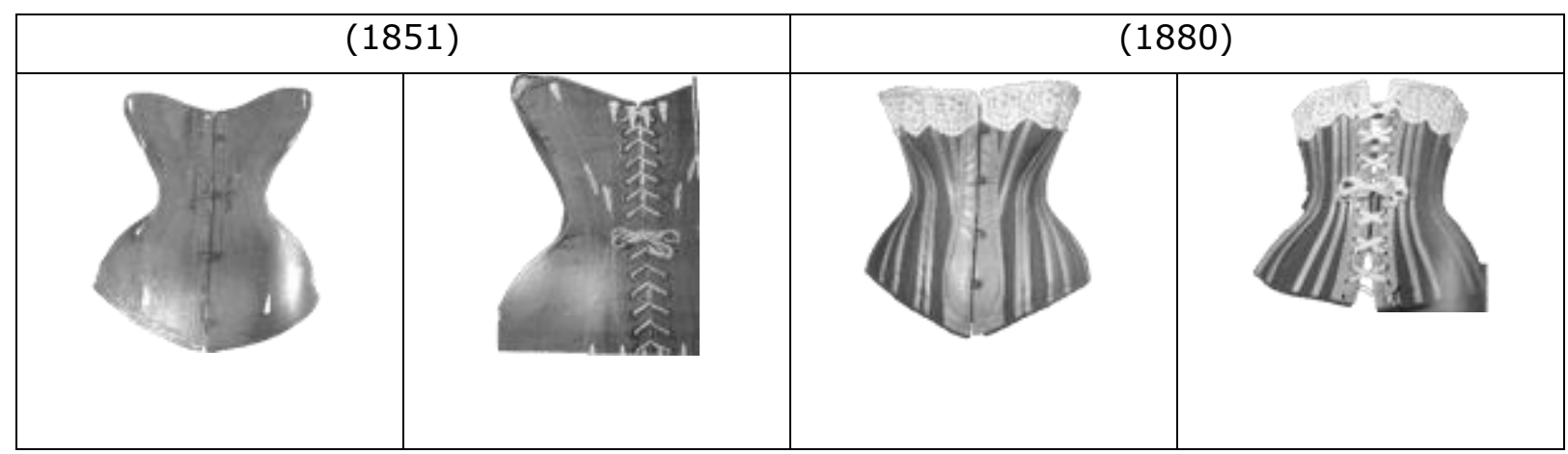

Figura 3: Corsets (1851-1880).

Fonte: Folli (2010). 


\subsection{Forma e função dos espartilhos}

Espartilhos e corsets eram usados para transformar três principais partes do corpo: 1) afunilar a cintura; 2) sustentar e acentuar o busto; 3) reposicionar os quadris. Estes três pontos moldaram a silhueta feminina sob a influência do ideal estético e político (BARBIER e BOUCHER, 2010; FOLLI, 2010; FONTANEL, 1998).

Além de modelar o corpo feminino, os redesigns e o uso dos espartilhos estiveram submetidos às modas regidas pela nobreza. Prova disso, ressaltam Barbier e Boucher (2010) e Fontanel (1998), foram as mudanças ocorridas durante o reinado de Luís XIV (1638-1715). Neste período, eram usadas a gourgandine - um espartilho amarrado e entreaberto na frente. Porém, quando a amante do rei, Madame de Montespan, precisou esconder suas oito gravidezes, introduziu a moda dos vestidos largos, e os espartilhos entraram em desuso. Depois, Madame de Montespan caiu em desgraça, e a moda dos espartilhos voltou.

Outras influências foram a política e as cruzadas médico-pedagógicas, engajadas em 1750, contra o uso dos espartilhos. Na França, o tema de deformidade dos corpos acompanhava o da degenerescência do regime, influenciada pela campanha de Rousseau de retorno à simplicidade e à natureza. Todos os entraves deveriam ser abolidos, dentre eles o uso dos espartilhos. Em meio a isso, os fabricantes de espartilhos criaram um corpete - a la Ninon, com barbatanas e mais curto na altura da cintura (FONTANEL, 1998).

Todavia, o processo de queda dos espartilhos foi moroso. Ainda no século XIX, com a moda da cintura de vespa, dos decotes baixos e seios separados, dentro de vestidos bufantes, houve uma explosão do uso dos espartilhos e o surgimento de novos modelos e processos de fabricação.

Por exemplo, em 1832, o suíço Jean Werley confeccionou espartilhos sem costuras, que saíam do tear com barbatanas, hastes e armações, prontos para ser vendidos. Em 1840, foi criado um sistema de cordões elásticos, denominado de sistema de atar à la 
paresseuse, que permitia o vestir e o desvestir sozinha. Em meados do século XIX, os espartilhos passaram a ser fabricados em série (FONTANEL, 1998; SALEN, 2011).

Nesse período, havia uma elevada variedade de formas e tamanhos de espartilhos, segundo Folli (2010), com o propósito de atender as diferentes ocasiões, tais como casamentos, usos matinais e noturnos, para viagens, para equitação, para cantar, para dançar, inclusive para nadar.

Entretanto, apesar das mudanças introduzidas nos projetos dos novos espartilhos, as implicações negativas na saúde das mulheres ganharam publicidade. E, por volta de 1870, ressalta Salen (2011), cresceu o sentimento de opressão relacionado ao uso do espartilho. Havia uma atenção rigorosa para os códigos do vestir, juntamente com os movimentos de mudanças do papel feminino na sociedade, tais como equivalência com os homens, o direito ao voto, a liberdade para trabalhar e ganhar dinheiro.

Mesmo assim, no fim do século XIX, os espartilhos ainda eram extremamente apertados $\mathrm{e}$ reduziam a mobilidade das mulheres (Figura 4). Por volta de 1898, a Rússia proibiu as meninas de usarem espartilhos nas escolas. Em 1902, o ministro da Instrução romeno também emitiu a mesma proibição, e a Bulgária, em 1904.

\begin{tabular}{|l|l|l|l|}
\hline \multicolumn{2}{|c|}{ Corset 1890} & 1890 & Silhueta em "S" (1906) \\
\hline & &
\end{tabular}

Fiqura 3: Corsets (1890-1906) compilados pela autora.

Fonte: Folli (2010).

Fonte: Folli (2010).

Fonte: Berg (2015).

Apesar do declínio do espartilho ter sido fortemente justificado com base em problemas de 
saúde, as mudanças políticas e do papel social da mulher foram fatores determinantes.

\subsection{A influência dos espartilhos no papel social das mulheres}

As mulheres que usavam espartilhos por volta de 1840, segundo Folli (2010) e Fontanel (1998) eram excessivamente sedutoras e pouco naturais. Comprimidas e elegantemente vestidas, essas mulheres ficavam incapacitadas para qualquer trabalho e precisavam da ajuda de serviçais para se vestir e se despir.

Crane (2006) acrescenta que, os espartilhos foram usados no século XIX e início do século $X X$ por mulheres abastadas. Ainda mais, o uso dos espartilhos era limitado entre mulheres da classe operária, não apenas pelo custo e pela limitação que era imposta às atividades físicas, mas também pelas diferenças de estilo de vida dentro da própria classe operária, tais como: estado civil; filhos; espaço rural ou urbano; se trabalhava no espaço doméstico ou no espaço externo ao lar; e o tipo de atividade exercida.

As afirmações de Crane (2006), estão fundamentadas no estudo da indumentária da classe operária dos Estados Unidos, da Inglaterra e da França nos séculos XIX e XX. A referida autora analisou os relatórios de Frédéric Le Play e de seus colaboradores, que pesquisaram, durante aproximadamente 60 anos, as famílias operárias francesas do século XIX e construíram um inventário detalhado sobre suas vestes.

Nessa época, as mulheres camponesas não usavam roupas de baixo. Costumavam vestir uma saia e uma camisa e por cima um colete atado por cordões, não muito apertado. Esse colete acentuava a cintura e sustentava os seios. Mas, diferentemente dos espartilhos, que eram atados nas costas, aqueles usados pelas camponesas eram atados na frente (BOUCHER, 2010; FONTANEL, 1998). Essa maior facilidade em vestir e desvestir estava associada ao fato de as mulheres camponesas se vestirem sozinhas.

Entretanto, segundo Folli (2010), do século XVI ao fim do século XIX, os espartilhos não foram 
questionados nem pela aristocracia, nem pela burguesia. Simbolicamente, representavam a superioridade e o prestígio da classe dirigente. Era um sinal de distinção do povo. Isso porque, ao contrário da mulher da burguesia e da nobreza, a mulher de condição modesta precisava trabalhar.

Contudo, o desuso dos espartilhos se consolidou durante a Primeira Guerra Mundial (1914-1918). De acordo com Fontanel (1998), principalmente porque, com os homens nos campos de batalhas, as mulheres camponesas assumiram o trabalho no campo; as comerciantes passaram a dirigir automóveis e, nos subúrbios, as fábricas foram ocupadas por operárias "munitionnettes", empregadas na indústria bélica, e as "midinettes", que trabalhavam na confecção de roupas.

Outra motivação foi a ausência de camareiras entre as burguesas, o que, segundo Fontanel (1998), levou-as a procurar por roupas mais fáceis de vestir e desvestir. Além disso, o excesso de ornamentação havia se tornado de mau gosto entre as inúmeras viúvas de guerra.

\section{SUTIÃS}

O primeiro sutiã foi comercializado pela Casa Cadolle. Sua fundadora, a francesa Herminie Cadolle, ao perceber que o espartilho estava se tornando arcaico, reformulou-o e criou o corpete para seios. Sua ideia consistia na inversão da força de suporte sustentar os seios por baixo e suspendê-los com o uso das alças apoiadas nos ombros. Diferentemente dos espartilhos, que tinham seu ponto de apoio nos quadris (FONTANEL, 1998).

Entretanto, apesar dessa invenção ter sido apresentada na Exposição Universal de 1889, não foi patenteada. Por isso, o título de criadora do primeiro sutiã foi registrado pela nova-iorquina Mary Phelps que, com a ajuda de sua empregada francesa, criou uma espécie de porta-seios usando dois lenços e fitas para bebê. Depois reproduziu o modelo para as suas amigas e patenteou sua invenção em 1914. 


\subsection{Forma e função dos sutiãs}

O termo sutiã é uma derivação da palavra francesa soutien, uma redução da expressão soutiengorge, que significa "sustenta seios". Para as francesas, o soutien tem a função de sustentar algo que pode cair. Enquanto que, para as espanholas, o sujetador tem a função de dominar algo que pode escapar (PIMENTA, 2002; SILVA, 2014). No continente americano, sob regência da língua anglo-saxônica, outra palavra francesa - brassiére - foi adotada e abreviada para bra, que se traduz em sutiã (SILVA, 2014).

Ambas as palavras - soutien e bra - foram adotadas no início do século $X X, e$, desde então, o artefato sutiã foi desenhado e redesenhado. Entretanto, apesar das variáveis existentes em cada modelo, sua estrutura básica torna alguns de seus elementos configurativos comuns à maioria dos sutiãs, conforme descrito na Figura 5.

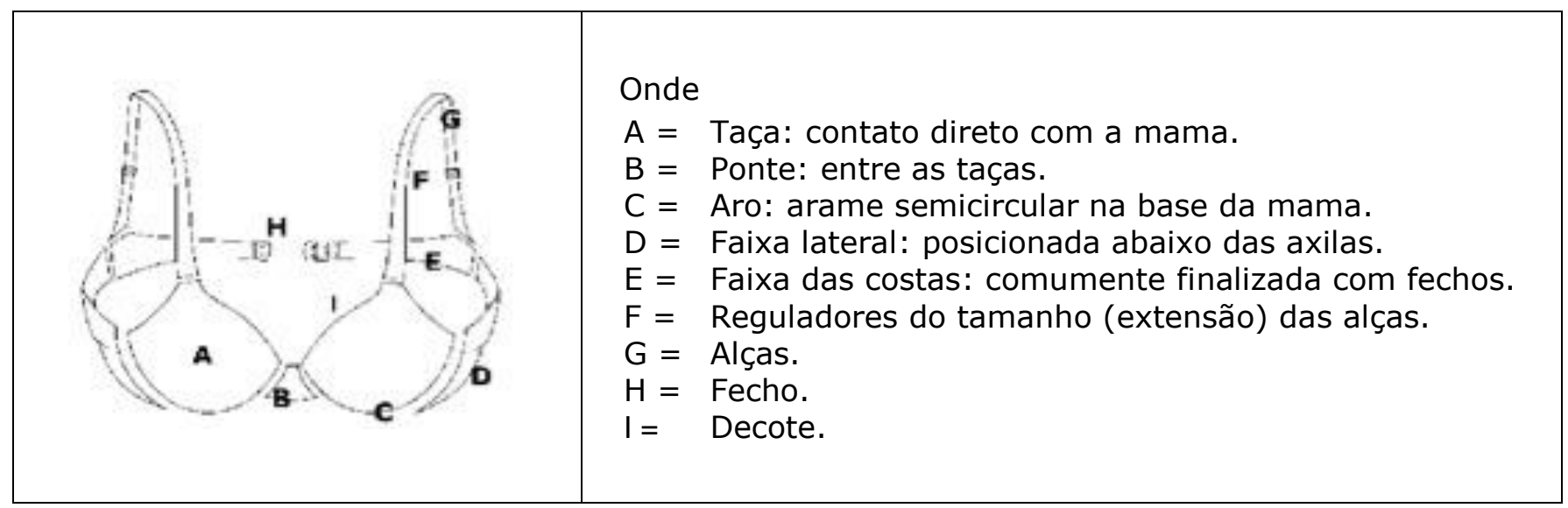

Figura 4: Estrutura básica do sutiã. Fonte: síntese da autora.

Com base na definição de Löbach (2001) e Wong (1998), pode-se dizer que a forma do sutiã é constituída das unidades de forma denominadas de taças, alças e faixa. E, cada uma dessas unidades são formadas por subunidades, que variam de acordo com as características configurativas:

1. As taças possuem diferentes formatos (Figura 5) e são constituídas por subunidades, como tecido externo, variavelmente, também por forro, enchimento espumado, aros e costuras; 
2. As alças, quando existentes, são formadas por subunidades com material de: tecido; elástico; ou tecido e elástico juntos. Além dos reguladores de comprimento. Também podem apresentar variações na largura e camadas (enchimento espumado);

3. A faixa circunda o tórax e se constitui a partir das seguintes subunidades: ponte, sob a taça, lateral, costas e fechos. Em alguns sutiãs, é subtraída a parte da faixa sob a taça e a ponte passa a ser uma unidade da forma. Os fechos podem ser posicionados em diferentes partes da faixa - frente, lateral ou costas.

Ainda com base no formato das taças, conforme representações na Figura 6, os modelos de sutiãs mais usuais são denominados, segundo Stalder (2009) e Dominy (2010), de: Triângulo; Meia-taça; Push-up; e Top.

\begin{tabular}{|c|c|c|c|c|}
\hline Triângulo & Meia-taça & Push-up & Cobertura Total & Top \\
\hline
\end{tabular}

Figura 5: Modelos de sutiãs, com base no formato das taças.

Fonte: Loungerie (2016) e Liz (2016).
Outro fator relevante, durante o século $X X$, foi a variedade de formas atribuídas ao sutiã, o que permitiu sua categorização em: 1) sutiã de moda; 2) sutiã esportivo; 3) sutiã para mulheres mastectomizadas. 0 que não descarta a existência de outras categorias tais como sutiãs para as fases da lactação e pós-cirúrgico.

Os sutiãs de moda, usados massivamente pelas mulheres nos mais variados contextos, em sua maioria têm foco na estética, por isso apresentam maior variação quanto aos modelos e formas disponíveis no mercado, além de coleções temporais. Por exemplo, Aiex e Martins (2013), ao analisar duas marcas brasileiras de sutiãs de moda, encontraram uma ampla oferta de modelos fashionistas com rendas, acessórios e alças estreitas. 
A exceção está em alguns modelos clássicos, praticamente inalterados ao longo do tempo, disponibilizados por algumas marcas, a exemplo da Duloren. Entretanto, segundo Risius (2012), o suporte oferecido pelo sutiã de moda é inferior àquele proporcionado pelo sutiã esportivo.

Provavelmente, porque os sutiãs esportivos ou tops, conforme cita Zhou (2011), foram projetados para fornecer maior suporte às mamas e diminuir seu movimento vertical durante realização de atividades físicas. Podem ainda ser do tipo: 1) Compressão comumente não possui taças separadas, projetado para restringir o movimento da mama por compressão e achatamento contra o tórax; 2) Encapsulado - com taças moldadas individualmente, para dar suporte individual a cada mama durante atividades físicas de maior impacto.

Apesar do alto desempenho dos sutiãs esportivos, têm sido menos adotados do que os "sutiãs de moda". Por exemplo, Bowles, Steele e Munro (2008), encontraram que entre as mulheres praticantes de atividades físicas o uso do sutiã de moda ainda é maior (34\%) do que do sutiã esportivo (32\%).

Posteriormente, Brown et al. (2014) verificaram que $o$ uso do sutiã esportivo é mais significativo durante a realização de atividades físicas de maior impacto em comparação com atividades físicas moderadas. A frequência e uso também foi maior entre as mulheres com mamas grandes do que entre as mulheres com mamas pequenas.

Outra característica relevante da estrutura do sutiã é o material empregado em sua confecção. Possui, inclusive, um papel importante no processo de popularização dessa veste, mediado pelos avanços tecnológicos na indústria têxtil, depois da Segunda Guerra Mundial.

Também é relevante o comportamento do tecido no ajuste do sutiã ao corpo. Por exemplo, para diferentes autores as malhas exercem melhor esse papel, por serem mais elásticas do que os tecidos planos (BARBIER e BOUCHER, 2010; SALEM，2010; UDALE, 2009). 
Quanto ao tipo de fibra, aquelas de origem natural e consideradas nobres se tornaram menos usuais do que as de origem artificial. É o caso da fibra de seda, cuja utilização restringiu-se às peças íntimas mais sofisticadas, portanto menos populares, dados os altos custos para sua obtenção - cultivo e beneficiamento. No lugar, as fibras sintéticas de poliéster e poliamida têm sido aplicadas massivamente na confeç̧ão de sutiãs (BARBIER e BOUCHER, 2010; UDALE, 2009).

A fibra natural de algodão também é utilizada na confecção de sutiãs, porém em baixa proporção quando comparada com a poliamida. Tanto o algodão quanto a poliamida comumente são combinadas com outra fibra elástica a fim de melhorar o ajuste do produto final ao corpo.

Essa maior utilização de fibras sintéticas, justifica-se principalmente pelo barateamento do processo produtivo e pela facilidade de manutenção e limpeza da peça confeccionada, tais como lavagem e secagem rápida. Além disso, nos últimos anos, os novos tecidos - resultantes da aplicação de tecnologias - propõem-se a reproduzir nas fibras sintéticas características de melhor respirabilidade e desempenho funcionais, como a inibição do crescimento de bactérias e fungos, dentre outros.

Entretanto, apesar do melhoramento nos tecidos sintéticos, Risius (2012) identificou que as mulheres maduras da classe média do sudeste da Inglaterra têm preferência por sutiãs de uso diário que sejam predominantemente confeccionados com malhas de algodão. Além disso, Aiex e Martins (2013), em pesquisa no Brasil, também identificaram que sutiãs de poliamida têm alta incidência na sudação de suas usuárias.

Apesar desses achados, os custos de produção dos tecidos com fibras sintéticas são menores, o que tornou as roupas íntimas de aparência similar à seda e ao cetim acessíveis às mulheres de contextos populares. E possibilitou a criação e produção de sutiãs com variedades de formas e funções, ao longo do século XX (Quadro 2). 


\begin{tabular}{|c|c|c|}
\hline Período & Sutiã & \\
\hline Século XIX & Corpete (1889): & $\begin{array}{l}\text { Sustentar seios e suspender com alças apoiadas nos } \\
\text { ombros. }\end{array}$ \\
\hline \multirow{2}{*}{$\begin{array}{l}\text { Século XX } \\
1900-1920\end{array}$} & Corpete de malha: & \\
\hline & Porta-seios (1913): & Função \\
\hline \multirow{4}{*}{$1920-1930$} & Sutiã andrógeno: & Achatar as mamas. \\
\hline & $\begin{array}{l}\text { Corpete de algodão e linho, } \\
\text { aberto na frente: }\end{array}$ & Cobrir os seios. Não oferecia sustentação. \\
\hline & $\begin{array}{l}\text { Corpete com bojo } \\
\text { e barbatanas horizontais: }\end{array}$ & Projetar a mama para frente. \\
\hline & $\begin{array}{l}\text { Sutiã triângulo de chiffon, } \\
\text { seda e renda de algodão: }\end{array}$ & Cobrir e decorar. Não oferecia sustentação. \\
\hline \multirow{7}{*}{$1930-1940$} & Triângulo com bojo (1930): & Cobrir os seios. Usado durante todo o século XX. \\
\hline & $\begin{array}{l}\text { Push-up - com bojo } \\
\text { e reforço na lateral: }\end{array}$ & Aproximar os seios. \\
\hline & $\begin{array}{l}\text { Sem alça, com barbatana } \\
\text { de aço e reforço elástico: }\end{array}$ & Combinar com a roupa externa. \\
\hline & Taças Alfabeto: & Encaixar mamas nas taças. \\
\hline & Taças com enchimento: & Aumentar os bustos pequenos. \\
\hline & Aros: & Deixar os seios mais curvos. \\
\hline & Alças elásticas: & Ajustar aos ombros. \\
\hline \multirow{3}{*}{$1940-1950$} & Sutiã sem alça: & Combinar com a roupa externa. \\
\hline & Com pespontado circular: & Deixar os seios pontudos e torneados. \\
\hline & O corset reaparece: & $\begin{array}{l}\text { Avolumar o busto e estreitar a cintura - Look Dior } \\
\text { (1947). }\end{array}$ \\
\hline \multirow{3}{*}{$1950-1960$} & Sutiã almofadado: & Aumentar os seios muito pequenos. \\
\hline & $\begin{array}{l}\text { Sem alça, com aro e } \\
\text { elástico: }\end{array}$ & Com parte elástica para segurar o sutiã no corpo. \\
\hline & $\begin{array}{l}\text { Peito de pombo - alças no } \\
\text { limite das axilas: }\end{array}$ & Aproximar os seios - estufados pela armação e alças. \\
\hline \multirow{2}{*}{$1960-1970$} & Segunda Pele: & Conforto. \\
\hline & Sutiãs para adolescentes: & Menor sustentação -modelos simples e delicados. \\
\hline \multirow{4}{*}{$1970-1980$} & Aro com cobertura: & Conforto - amortecer o atrito. \\
\hline & Longo: & Pode ser usado como roupa externa. \\
\hline & Tricotado (Efêmero): & Não oferecia sustentação - alegres e coloridos. \\
\hline & Sem costura: & Diminuir o atrito. \\
\hline \multirow{4}{*}{$1980-1990$} & A lycra ressurge melhorada: & $\begin{array}{l}\text { Misturada a tecidos - como a seda, o crepe, o tule e a } \\
\text { renda. }\end{array}$ \\
\hline & Nadador: & Combinar com regatas e cavas grandes. \\
\hline & Surge a microfibra: & Conforto. \\
\hline & Sofisticados: & Para sedução. Marcas como a italiana La Perla. \\
\hline \multirow{4}{*}{$1990-2000$} & Sutiã pespontado pontudo: & Primeira versão de Jean-Paul Gaultier para Madonna. \\
\hline & Push-up: & Aproximar o seios. \\
\hline & Corset: & da estilista Vivienne Westwood. \\
\hline & Sutiãs com funções extras: & Hidratação, massagem e proteção UV. \\
\hline $\begin{array}{l}\text { Século XXI } \\
2000-2010\end{array}$ & $\begin{array}{l}\text { Expansão dos sutiãs para } \\
\text { usos específicos: }\end{array}$ & $\begin{array}{l}\text { Esportivo, amamentação, pós-cirúrgico. } \\
\text { Releituras das invenções e funções anteriores. }\end{array}$ \\
\hline $2010-2016$ & Sutiã pespontado pontudo: & Segunda versão de Jean-Paul Gaultier para Madonna. \\
\hline
\end{tabular}

Quadro 2: Formas e Funções dos Sutiãs.

Fonte: Compilação da autora com base em Barbier e Boucher (2010), Berg (2015), Fontanel (1998), Salen (2011),

Stalder (2009). 
Conforme sintetizado no Quadro 2, o sutiã foi inventado e reinventado ao longo do século XX. Dentre eles, é importante destacar que na segunda metade da década de 1920, as dimensões do corpo feminino passaram a ser estudadas com o objetivo de propor roupas mais confortáveis.

De acordo com Fontanel (1998), a casa australiana Berlei havia encarregado, em 1926, dois professores da Universidade de Sydney a realizarem um levantamento antropométrico. Mais tarde, por volta de 1931, os irmãos Warner criaram as taças de profundidade de $A-D$, e depois as alças elásticas e o bojo moldado.

Em 1935, foram criados os bojos com enchimento para aumentar os bustos pequenos $\mathrm{e}$ depois os sutiãs de armação, que desapareceram por um tempo e voltaram a ser usados nos anos 1950.

Na década de 1960, segundo Fontanel (1998) houve um processo de simplificação, com a produção de modelos mais simples, delicados e confortáveis para o público adolescente. Também foram criadas alças estreitas reguláveis. Na década seguinte (1970), a marca francesa Huit colocou no mercado o primeiro sutiã de taça moldado, que havia sido patenteado por Warner antes da Guerra (Figura 7).

\begin{tabular}{|l|l|l|}
\hline 1950 & 1970 & 1970 \\
\hline & & \\
\hline
\end{tabular}

Figura 6: Corpetes e sutiãs de 19501970.

Fonte: Salen (2011).

$\mathrm{Na}$ década de 1980, ainda segundo Fontanel (1998), a criação da microfibra melhorou a textura da malha. Além disso, a Revolução Têxtil possibilitou a criação de sutiãs com alto nível de refinamento, a exemplo dos produtos criados pela marca Italiana $L a$ Perla que se impuseram na França nesse período. 
No cenário atual, a La Perla vende sutiãs sofisticados, como o modelo Tulles Nervures Bandeau, que chega a custar 340 Euros (junho/2015) - taças almofadadas, $14 \%$ algodão e $86 \%$ poliéster, alças ajustáveis e removíveis, tecido $12 \%$ elastano, $33 \%$ nylon, $55 \%$ seda (

Figura 7 - 2015).

\begin{tabular}{|c|c|c|c|c|}
\hline 2004 & $2006-2007$ & 2008 & $2008-2009$ & 2015 \\
\hline & & &
\end{tabular}

Figura 7: Sutiãs 2004-2015, compilados pela autora.

Fonte: Bouche (2010). Fonte: Folli (2010). Fonte: Folli (2010). Fonte: Folli (2010). Fonte: La Perla (2016).

Desde os anos 1990, conforme ressaltam Barbier e Boucher (2010), a roupa íntima, em alguns casos, passou a ter o status de roupa exterior, tornando-se cada vez mais frequente sua apresentação por diferentes designers. É o caso da estilista Deborah Marquit, que em 2004 lançou um editorial em que o sutiã de renda aparecia sob a camisa entreaberta.

Mostrar a renda do sutiã ou detalhes de sua forma tem sido um dos recursos recorrentes na moda - a exemplo dos sutiãs denominados Strappy bra, que, literalmente, significa "sutiãs com tiras" (Figura 8).

\begin{tabular}{|c|c|c|c|c|}
\hline S/data & 2016 & 2016 & 2016 \\
\hline & &
\end{tabular}

Figura 8: Sutiãs 2016. Fonte: Folli (2010).
Fonte: Victoria's Secret (2016).
Fonte: Victoria's Secret (2016).
Fonte: Strappy bra Hope (2016).
Fonte: La Perla (2016). Conte: La Perla (2016). 
Em meio a essas mudanças, a casa Cadolle, que comercializou o primeiro sutiã, continua produzindo peças sob medida em seu ateliê. Também produz sutiãs para o prêt-à-porter, que são comercializados em lojas espalhadas por diversas partes do mundo. Segundo Thomas (2008, p.305), usar um sutiã feito sob medida pelo ateliê Cadolle representa o que ele chama de novo luxo - "atenção pessoal legítima, materiais raros, artesanato fino" - , que foca mais no resultado do que na arte.

Também cresceram marcas de lingeries dentro do prêt-à-porter de luxo, a exemplo da H\&M, Kookai, Morgan. De acordo com Barbier e Boucher (2010), a marca Christian Dior tem licença para produzir lingerie desde 1954, e Nina Ricci começou a produzir em 1978. Ambas foram precursoras desse movimento. Algumas celebridades também lançaram suas próprias marcas de lingerie, a exemplo de Kylie Minogue, Jennifer Lopez e Elle McPherson. Gisele Bündchen também criou uma linha de lingerie em parceria com a Hope.

Outros nichos são as necessidades específicas, algumas temporárias, como a fase de lactação e pósoperatória. Marcas como DeMillus, Yoga, Ameona, dentre outras, colocaram no mercado nacional e internacional os sutiãs pós-operatórios, a fim de atender uma lacuna que havia anteriormente.

Esses novos produtos tem sido respaldo por pesquisas científicas. Por exemplo, Laura, Clark e Harvey (2004) compararam o uso do sutiã pósoperatório da marca Ameona ( $90 \%$ algodão e $10 \%$ spandex) com o uso de ataduras em 58 pacientes. E constataram que o desconforto pós-operatório pode ser diminuído pelo uso de um sutiã bem ajustado, mais do que usando ataduras.

\subsection{A influência dos sutiã no papel social das mulheres}

O declínio dos espartilhos e a ascensão dos sutiãs no início do século $X X$, conforme supracitado, teve, por pano de fundo, as mudanças resultantes das 
Duas Grandes Guerras. Fato que requereu a atuação das mulheres no mercado de trabalho.

Nas primeiras décadas do século $X X$, as novas roupas externas, mais naturais, sobretudo aquelas criadas pelos estilistas Paul Poiret e Madeleine Vionnet, requeriam um novo tipo de suporte interno. $\mathrm{E} O$ surgimento do sutiã também veio atender a estas novas demandas.

Além disso, a rápida evolução do sutiã durante o século $X X$ esteve atrelada à união entre a moda e a indústria de massa, que segundo Avelar (2009) deu origem ao prêt-à-porter por volta dos anos 1960.

$\mathrm{Na}$ maior parte dos contextos laborais, o sutiã incorporou o papel de conservar os seios discreto sob as roupas sóbrias. Desde então, é possível afirmar que, do ponto de vista sociocultural, o uso do sutiã no ambiente formal de trabalho tornou-se um hábito ou quase uma obrigação. O que pode ser constatado na pesquisa de Odebiyi et al. (2015) realizada na Nigéria, na qual 40,5\% das mulheres afirmaram usar sutiãs apenas nas horas de trabalho e, 43,3\% o dia inteiro.

\section{CONSIDERAÇÕES FINAIS}

Este artigo apresentou uma descrição estrutural e diacrônica das vestes íntimas usadas para sustentar as mamas - protossutiãs, espartilhos e sutiãs.

A trajetória histórica, esquematizada no Diagrama 1 , permitiu identificar as diferentes estruturas projetuais dos precursores e dos sutiãs, e, igualmente, a relação entre as funções anatômicas, exercidas pelos protossutiãs e espartilhos, e aquelas transferidas para o sutiã contemporâneo. Pode-se dizer, portanto, que funções como sustentação, cobertura/exibição dos seios femininos e modelagem da mama e da silhueta, sejam pelos efeitos de diminuir, achatar, levantar ou aumentar as mamas, são comuns entre precursores e sutiãs.

Outra inferência possível, com base nas usuárias das referidas roupas íntimas, expôs que, enquanto os protossutiãs e os espartilhos atuavam 
como mantenedores de um modelo de status quo, o sutiã representa uma mudança de paradigma. Portanto, o papel social exercido por esta veste coloca-a numa posição além da intimidade.

Quer dizer, os protossutiãs, durante a Antiguidade, eram usados apenas pela nobreza, como sinal de status. Nesse período, as escravas não cobriam as mamas. Similarmente, os espartilhos, da Idade Média ao século XIX, também foram adotados, principalmente, pelas mulheres da nobreza e da burguesia, que não exerciam atividades profissionais e dispunham de serviçais para ajudá-las nas tarefas de vestir e despir.

- Corset

- Vasquim

- Le Corps Piqué

- Gourgandine

- La Ninom

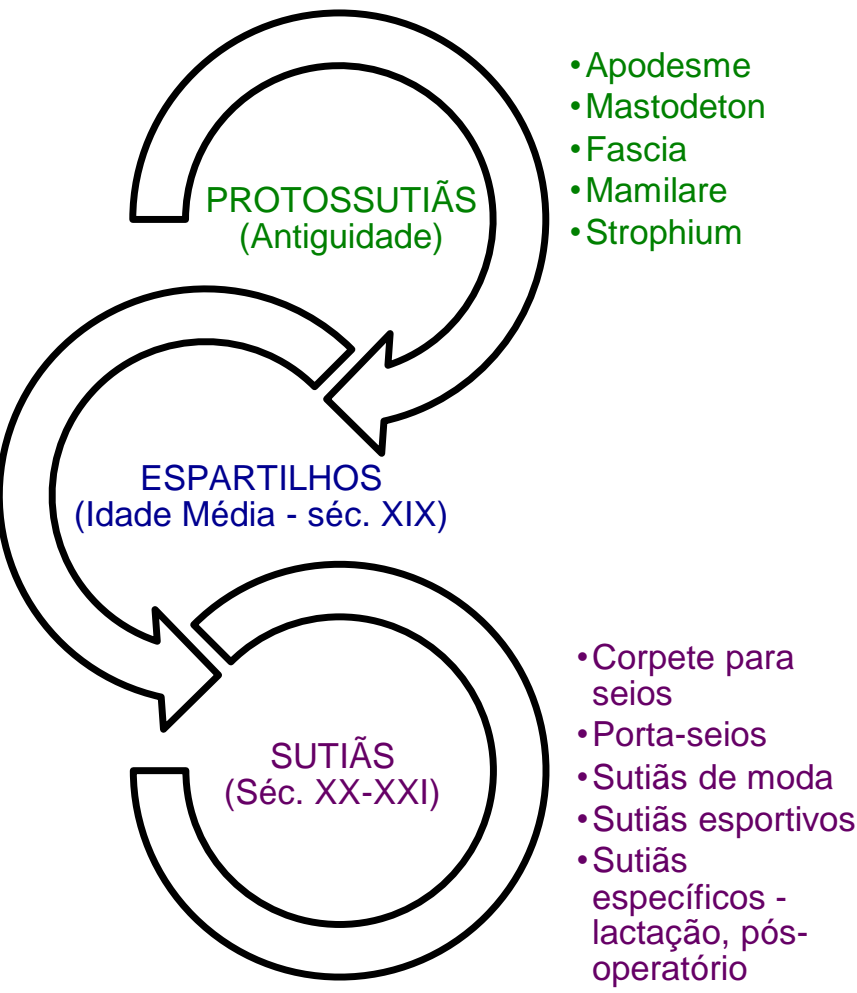

Diagrama 1: Síntese da análise diacrônica dos protossutiãs, espartilhos e sutiã. Fonte: compilado pela autora.

Ainda na era dos espartilhos, as operárias e camponesas usavam uma peça semelhante - colete - , numa versão mais simples, com amarrações na frente, dada a mobilidade necessária para as tarefas de vestir e despir-se sozinhas, assim como a execução das atividades laborais. 
No início do século $X X$, as novas demandas sociais e do mundo do trabalho, sobretudo durante a Primeira Guerra, contribuíram na transição do espartilho para o sutiã. Mais que isso, os avanços tecnológicos ocorridos para atender as necessidades da Segunda Guerra também colaboraram para o desenvolvimento tecnológico na indústria têxtil e para uma rápida democratização do sutiã, se comparada com o período de uso dos espartilhos.

Em menos de meio século, o sutiã se popularizou e passou a ser usado por mulheres pertencentes a todas as categorias sociais. E mesmo que, individualmente, usar um sutiã seja algo facultativo e as variações entre peça de luxo e peça popular coloquem suas usuárias em diferentes nichos de mercado, seu uso se tornou quase que indispensável, em ambientes públicos e sociais, sobretudo naqueles destinados ao trabalho produtivo.

\section{Referências}

AIEX, Viviane Mantovani; MARTINS, Suzana Barreto. Análise Dos Parâmetros Que Influenciam Na Compra De Sutiãs Tamanhos Superiores a 46. Revista Projética. Londrina, v.4, n.1, p. 137-160, Jan./Jun. 2013. Disponível em: <http://www.uel.br/revistas/uel/index.php/projetica>. Acesso em: 20 mar. 2014.

AVELAR, Suzana. Moda: Globalização e Novas Tecnologias. São Paulo: Estação das Letras e Cores Editora, 2009.

BARBIER, Muriel; BOUCHER, Shazia. The Story of Women's Underwear. New York USA: Parkstone Press International, 2010.

BERG, Ana Laura Marchi. Corset: interpretações da forma e da construção. São Paulo: Editora Senac, 2015.

BONSIEPE, Guy. Metodologia Experimental: desenho industrial. Brasília: CNPq/Coordenação Editorial, 1984.

BOUCHER, François. História do Vestuário no Ocidente: das origens aos nosso dias. Tradução de André Telles. São Paulo: Cosac Naify, 2010. 
BOWLES, Kelly-Ann; STEELE, Julie R.; MUNRO, Bridget J. What Are The Breast Support Choices Of Australian Women During Physical Activity? Journal Sports Med. n. 42. p. 670-673. Jun. 2008.

BROWN, Nicola; WHITE, Jennifer, BRASHER , Amanda; SCURR, Joanna. An Investigation Into Breast Support And Sports Bra Use In Female Runners Of The 2012 London Marathon. Journal of Sports Sciences. p. 1-9, Jan. 2014.

CRANE, Diana. A moda e Seu Papel Social: classe, gênero e identidade das roupas. Tradução de Cristiana Coimbra. São Paulo: Editora Senac São Paulo, 2006.

DOMINY, Katie. Contemporary Lingerie Design. Londres, Reino Unido: Laurence King, 2010.

FOLLI, Anna. Lingerie: the evolution of seduction. Tradução de Catherine Howard. Vercelli, Italy: White Star, 2010.

FONTANEL, Béatrice. Sutiãs e Espartilhos: uma história de sedução. Tradução de Maria Cecília D'Egmont e Olívia Martins. Rio de Janeiro: GMT Editores, 1998.

HOPE. Disponível em: < http://www.hopelingerie.com.br >. Acesso em: 20 Fev 2016.

LA PERLA. Disponível em: < https://www.laperla.com>. Acesso em 25 Fev 2016.

LAURA, Sharon; CLARK, David; HARVEY, Fiona. Patient Preference for Bra or Binder After Breast Surgery. ANZ Journal of Surgery. v.74, p.463-464, 2004.

LIZ. Disponível em: < https://www.liz.com.br/sport/>. Acesso em: 25 Jan 2016.

LOBÄCH, Bernd. Design Industrial: base para configuração dos produtos industriais. Trad. Freddy Van Camp. São Paulo: Edgard Blücher, 2001.

LOUNGERIE. Disponível em: <

https://www.loungerie.com.br/produtos/sutia-perfeito>. Acesso em: 25 Jan 2016.

ODEBIYI, Daniel O.; AWETO, Happiness A.; GBADEBO, Olumide A.; OLUWOLE, Ayodeji A.; AIYEGBUSI, Ayoola I; OLAOGUN, Matthew O; LEE, Lester J. Association between suitability of bra fit and pectoral girdle myalgia in Nigerian women. International Journal of Therapy and Rehabilitation. v. 22, n. 9, p. 428-433, Sep, 2015.

PIMENTA, Reinaldo. A casa da Mãe Joana. Rio de Janeiro: Elsevier, 2002.

RISIUS, Debbie. An investigation of Breast Support for Older Women. Tese (Doutorado) - University of Portsmouth, United Kingdom, 2012.

ROSSETI, Ana. Roupas íntimas: o tecido da sedução. Trad. Eduardo Brandão. São Paulo: Martins Fontes, 1995.

SALEM, Vidal. Tingimento têxtil: fibras, conceitos e tecnologias. São Paulo: Blucher: Golden Tecnologia, 2010. 
SALEN, Jill. Vintage Lingerie: historical patterns \& techniques. Reino Unido: Anova Books Company Ltda, 2011.

SILVA, Deonísio da. De Onde Vêm As Palavras: origem e curiosidades da língua portuguesa. 17 ed. Rio de Janeiro: Lexikom, 2014.

STALDER, Erika. Moda: um curso prático e essencial. Tradução de Maíra Gonçalves Malosso. São Paulo: Marco Zero, 2009.

STEELE, Valerie. Fetiche: moda, sexo e poder. Tradução de Alexandre Jordão. Rio de Janeiro: Rocco, 1997

THOMAS, Dana. Deluxe: como o luxo perdeu o brilho. Tradução de Ana Gibson. Rio de Janeiro: Elsevier, 2008.

UDALE, Jenny. Fundamentos do Design de Moda: tecidos e moda. Tradução de Edson Furmankiewicz. Porto Alegre: Bookman, 2009.

VICTORIA'S SECRET. Disponível em: < https://www.victoriassecret.com>. Acesso em 25 Fev 2016.

WONG, Wucius. Princípios de Forma e Desenho. Trad. Alvamar Helena Lamparelli. São Paulo: Martins Fontes, 1998.

ZHOU, Jie. New Methods Of Evaluating Breast Motion In Braless And Sports Conditions. Tese (Doutorado - Ph.D.) - Institute of textiles and clothing. The Hong Kong Polytechnic University. China, 2011. 